\title{
Factors associated with appropriate inhaler use in patients with COPD - lessons from the REAL survey
}

This article was published in the following Dove Press journal: International Journal of COPD

\author{
David Price ${ }^{1,2}$ \\ Dorothy L Keininger ${ }^{3}$ \\ Boomi Viswanad ${ }^{4}$ \\ Matthias Gasser ${ }^{5}$ \\ Susann Walda ${ }^{5}$ \\ Florian S Gutzwiller ${ }^{3}$ \\ 'Division of Applied Health \\ Sciences, Academic Primary Care, \\ University of Aberdeen, Aberdeen, \\ UK; ${ }^{2}$ Observational and Pragmatic \\ Research Institute, Singapore; \\ ${ }^{3}$ Novartis Pharma AG, Basel, \\ Switzerland; ${ }^{4}$ Novartis Healthcare \\ Pvt. Ltd., Hyderabad, India; ${ }^{5}$ GfK \\ Switzerland AG, Basel, Switzerland
}

Correspondence: David Price Academic Primary Care, University of Aberdeen, Polwarth Building, Foresterhill, Aberdeen AB25 2ZD, UK Tel +65 68029724

Email dprice@opri.sg
Background: Nonadherence to medication and incorrect use of inhalers represent significant barriers to optimal disease management of patients with chronic obstructive pulmonary disease (COPD). Thus, health care professionals (HCPs) play a critical role in educating their patients on appropriate inhaler use and in ensuring medication adherence. However, many patients do not receive appropriate inhaler training or have not had their inhaler technique checked.

Methods: The Real-life Experience and Accuracy of inhaLer use (REAL) survey was a computer-assisted, telephonic survey consisting of 23 questions gathering real-world information on correct inhaler use, inhalation technique, device attributes, adherence, dosing accuracy, training, correct device use, ease of use, and factors that influence patient adherence in commercially available inhalers delivering COPD maintenance therapy. All results are based on patient-reported data.

Results: The survey was conducted between January 4, 2016 and February 2, 2016. A total of 764 patients using various inhalers $\left(\right.$ Breezhaler $^{\circledR}=186$; Ellipta $^{\circledR}=191$; Genuair $^{\circledR}=194$; Respimat $^{\mathbb{R}}=201$ ) with mild to very severe COPD, with a mean \pm SD age $56 \pm 9.8$ years, completed the survey. Patient self-reported adherence was significantly lower in younger patients compared to older patients $(p=0.020)$. Eighty-three percent of patients indicated that a demonstration (in-person) was "very helpful" versus 58\% for video. Patient preferences for training methods were as follows: demonstration of inhaler use (83\%), video $(58 \%)$, instructions for use $(51 \%)$, and leaflet (34\%). Twenty-nine percent of patients had not been checked to see if they were using their device correctly by a HCP within the last two years. Patients who were checked were significantly more adherent than unchecked patients $(p=0.020)$. The majority of the patients using Breezhaler reported either being very confident or confident of having taken a full dose, which was higher than those using Genuair, Ellipta ( $\alpha=0.05)$, and Respimat $(\alpha=0.05)$. Treatment adherence in the last 30 days was highest with Breezhaler followed by Respimat, Ellipta, and Genuair.

Conclusion: The REAL survey identified attributes that influenced patient adherence and optimal inhaler use. Predictive attributes that influence patient adherence which HCPs should be aware of include age and disease severity. Modifiable attributes which the HCP can influence include correct inhaler use training, choice of training methods, checking patient inhaler technique at subsequent visits, and device selection. Inhalers are integral in the effective management of patients with COPD; it is therefore important that patients use the inhaler correctly and have full confidence in the dosage.

Keywords: chronic obstructive pulmonary disease, survey, inhaler use, adherence, dose confidence, double dosing

\section{Background}

Inhaled therapy remains the cornerstone of chronic obstructive pulmonary disease (COPD) therapy. Inhaler devices facilitate the rapid delivery of small doses of drug 
to the lungs to achieve high local concentrations at the targeted site, thereby reducing the risk of adverse effects as compared with systemic therapy. ${ }^{1}$ Effective inhaled therapies for the treatment of COPD include bronchodilators and corticosteroids, most commonly delivered using pressurized metered-dose inhalers and dry powder inhalers. ${ }^{1,2}$ Effective treatment may be influenced by choice of inhaler device as specific device attributes may impact a patient's satisfaction and adherence with therapy., ${ }^{3,4}$ Due to the chronic nature of COPD, long-term self-administration of medications is paramount for preventing disease progression. Adherence is the extent to which health behavior reflects a health plan constructed and agreed to by the patient as a partner with a clinician in health care decision-making. ${ }^{5}$ Adherence to medication is defined as successful initiation, implementation, and persistence to treatment and is fundamental in optimal disease management. ${ }^{6,7}$ Correct inhaler technique ensures that a full dose is received. Between 28\% and $68 \%$ of patients use their inhalers incorrectly, ${ }^{8}$ which may result in ineffective management of COPD. ${ }^{9}$

There is increasing evidence that suggests correct inhaler technique is fundamental for effective therapy and that inhaler device type and mastery play important roles in improving adherence, clinical outcomes, health-related quality of life, and use of health care resources in patients with asthma and/or COPD. ${ }^{10-12}$ A recently published study showed critical errors are associated with COPD exacerbations, and critical errors are more common with non-breath-actuated inhalers. ${ }^{13}$ Poor inhaler technique, however, can significantly reduce effective delivery of the respirable fraction of the emitted dose that reaches the lungs. ${ }^{10}$ Studies have shown that many patients are not confident that they are using their inhaler correctly. ${ }^{9} \mathrm{Up}$ to $94 \%$ of patients have demonstrated incorrect inhaler technique in clinical studies with either conventional pressurized metered-dose inhalers or dry powder inhalers. ${ }^{1}$

Unfortunately, a large proportion of patients also lack effective training from health care professionals (HCPs) on proper use of an inhaler device, with evidence suggesting that $39 \%-67 \%$ of HCPs do not train their patients on the correct use of their inhalers. ${ }^{14}$ Additionally, few patients are systematically checked at subsequent visits after the first prescription of an inhaler, ${ }^{15}$ despite the Global Initiative for Chronic Obstructive Lung Disease guidelines suggesting that physicians regularly assess patients for correct device use. ${ }^{16}$

HCPs cite patient satisfaction and ease of use as one of the most important attributes when selecting an inhaler device for patients, ${ }^{17}$ and these attributes can also affect treatment adherence and effectiveness. ${ }^{14}$ In fact, treatment adherence has been shown to be modestly associated with inhaler satisfaction, better health status, and less frequent COPD exacerbations, although other factors are also likely to be involved. ${ }^{18}$ While patient satisfaction is important, correct inhaler technique is crucial as it can impact treatment outcomes. ${ }^{17}$

The Real-life Experience and Accuracy of inhaLer use (REAL) survey was a computer-assisted, telephonic survey conducted in patients with COPD to gather real-world information on inhaler use, including information on the level of device training provided to the patients through to correct device use (adherence, correct dosing) and ease of use.

The objective of the REAL survey was to evaluate realworld information on device training and factors that influence patient adherence in commercially available inhalers delivering COPD maintenance therapy via the Breezhaler ${ }^{\circledR}$ (Novartis AG, Basel, Switzerland), Ellipta ${ }^{\circledR}$ (GlaxoSmithKline, London, UK), Genuair ${ }^{\circledR}$ (Almirall, Barcelona, Spain), or Respimat ${ }^{\circledR}$ (Boehringer Ingelheim Pharma GmbH, Ingelheim, Germany) devices. The REAL survey results should serve as a guide to support good treatment practice for HCPs, help to further understand factors that promote adherence to medication, and enhance effective management of COPD.

\section{Methods}

The REAL survey was a 20-minute computer-assisted, telephonic survey consisting of 23 questions including (Table S1) 16 closed-ended questions, 6 closed-ended questions where respondents were asked to explain an answer, and 1 open-ended question. The questions were derived from the Inhaler technique assessment initiative Helping Asthma in Real-life Patients and Optimum Patient Care COPD review questionnaires. The authors as a committee developed the REAL survey based on aforementioned questionnaires following a process of pretesting and expert review. Patients from 9 countries, Brazil, Canada, France, Germany, Italy, Japan, the Netherlands, UK, and USA, were surveyed. To ensure a representative global sample, patients on multiple continents were included in the study. A telephonic survey was selected as to ensure no limitations due to access or ability to use other technologies. The survey data were not weighted. The survey was conducted between January 4, 2016 and February 2, 2016. This was a noninterventional market research study, and ethics approval was not required in accordance with the European Pharmaceutical market Research Association (ephmra.org). All patients provided written informed consent at the beginning of recruitment and oral informed consent at the beginning of the telephone interview.

Patients included in the study were aged 40-75 years diagnosed with mild to very severe COPD by a general 
physician or a pulmonologist, were using at least one of the 4 devices (Breezhaler, Ellipta, Genuair, or Respimat) on a daily basis (maintenance therapy), and must have not participated in any primary market research study on breathing problems within the 3 months prior to the survey. Patients were primarily selected upon physician referral, patientreported diagnosis, and experience with the inhaler devices included in this study. There was a limit on patient numbers for each device per country.

Patient-reported data on correct inhaler use (training and checks for correct use), inhalation technique, and device attributes (ease of use and confidence of inhaling full dose), and adherence and dosing accuracy data were collected. Key assessments used in the REAL survey are shown in Table 1. Demonstration of patient training was either in-person training by a HCP or by a virtual video presentation. All adverse events in relation to usage of Novartis' Breezhaler device were reported within 24 hours to the respective country-specific Novartis drug safety departments (data on file). Significance testing was conducted using a $\chi^{2}$ test for comparisons of proportions applying a $z$-test. Significance levels were set at $\alpha<0.05$.

Table I Key assessments used in the REAL survey

\begin{tabular}{|c|c|}
\hline Question & Variable \\
\hline Confidence in taking & Very low confidence \\
\hline \multirow[t]{4}{*}{ a full dose } & Low confidence \\
\hline & Neither high nor low confidence \\
\hline & Confident \\
\hline & Very confident \\
\hline Inhaling correct dose & Number of inhalations/puffs \\
\hline Self-reported & Patients were considered fully adherent if \\
\hline adherence & $\begin{array}{l}\text { they reported having taken their medication } \\
\text { every day within the last } 30 \text { days }\end{array}$ \\
\hline \multirow[t]{5}{*}{ Ease of use } & Very difficult \\
\hline & Somewhat difficult \\
\hline & Neither difficult nor easy \\
\hline & Somewhat easy \\
\hline & Very easy \\
\hline Did you ever receive & Yes \\
\hline any training on how & If Yes, how did the patient receive training: \\
\hline \multirow[t]{6}{*}{ to use the device? } & Leaflet \\
\hline & IFU \\
\hline & Video \\
\hline & Demonstration \\
\hline & Other \\
\hline & No \\
\hline Training effectiveness & Very unhelpful \\
\hline (helpfulness of & Somewhat unhelpful \\
\hline specific methods & Neither helpful nor unhelpful \\
\hline mentioned by & Somewhat helpful \\
\hline patient) & Very helpful \\
\hline
\end{tabular}

Abbreviations: IFU, instructions for use; REAL, Real-life Experience and Accuracy of inhaler use.

\section{Results}

A total of 764 patients $($ Breezhaler $=186$; Ellipta $=191$; Genuair $=194$; Respimat $=201$ ) with mild to very severe COPD, with a mean \pm SD age $56 \pm 9.8$ years, completed the survey; $51 \%$ and $49 \%$ of patients were male and female, respectively. The majority of patients (55\%) reported moderate COPD severity with a mean time since diagnosis of $4.7 \pm 5.2$ years; $68 \%$ of patients were diagnosed by a pulmonologist.

Patient demographics are shown in Table 2. No significant differences were observed between devices and disease severity. The majority of patients had used the device for more than a year (Figure 1). There was no significant difference in length of use between devices.

The patient population for the older than 65 years group was smaller $(\mathrm{N}=163)$ than the 65 years and under $(\mathrm{N}=601)$ group. Younger patients were significantly more likely to have mild and moderate disease compared to older patients (Table 3). Patient COPD severity tended to increase from each increasing age group.

Patient self-reported adherence is shown in Table 4. Patient adherence was significantly lower in patients aged $\leq 65$ years compared to patients aged $>65$ years $(p=0.020)$. No significant difference in adherence was observed between genders, disease severity or time since diagnosis. No significant difference in confidence of inhaling full dose was observed for gender, age, disease severity, or time since diagnosis.

Influence of training is shown in Table 5. Trained respondents were significantly more confident that the correct dose was taken. Approximately $30 \%$ of all patients reported not having received any training on inhaler use. Of the $70 \%$ of patients that received training, the most common patient preference for training was demonstration of inhaler use (83\%) followed by video (58\%), instructions for use $(51 \%)$, and leaflet (34\%) (Figure 2). Adherent patients were significantly more often trained with a demonstration than nonadherent patients $(p=0.037)$. Adherent patients were significantly more often trained by a pulmonologist than nonadherent patients $(p=0.001)$.

Training was mainly performed by pulmonologists (41.3\%), pharmacists $(20.2 \%)$, nurses $(18.1 \%)$, general physicians $(12.0 \%)$, or others (8.4\%) (Figure S1). Pulmonologists who diagnosed a patient as having COPD were most likely to train the patients themselves, whereas general physicians who diagnose the patient were more likely to delegate training to pulmonologists, pharmacists, and nurses.

Figure 2 shows that $83 \%$ of patients indicated demonstration was "very helpful" versus 58\% for video. Patient preferences 
Table 2 Patient demographics

\begin{tabular}{|c|c|c|c|c|c|c|c|c|c|c|}
\hline Inhaler & Total & Germany & the Netherlands & Brazil & Japan & France & Italy & UK & USA & Canada \\
\hline Breezhaler ${ }^{\circledR a}$ & $n=186$ & 37 & 17 & 36 & 17 & 27 & 22 & 15 & $0^{\mathrm{a}}$ & 15 \\
\hline Ellipta $^{\circledR}$ & $n=191$ & 19 & 10 & 28 & 12 & 26 & 24 & 22 & 25 & 25 \\
\hline Genuair ${ }^{\circledR b}$ & $\mathrm{n}=194$ & 35 & 20 & $0^{\mathrm{b}}$ & 17 & $0^{\mathrm{b}}$ & 23 & 32 & 33 & 34 \\
\hline Respimat $^{\circledR}$ & $n=201$ & 22 & 6 & 24 & 26 & 26 & 23 & 19 & 27 & 28 \\
\hline Total & $n=764^{c}$ & $110^{c}$ & 53 & 88 & $70^{c}$ & $77^{c}$ & 92 & $87^{c}$ & 85 & 102 \\
\hline \multicolumn{11}{|l|}{ Demographics } \\
\hline \multicolumn{11}{|l|}{ Sex } \\
\hline Male & $51 \%$ & $50 \%$ & $47 \%$ & $24 \%$ & $81 \%$ & $47 \%$ & $59 \%$ & $61 \%$ & $48 \%$ & $50 \%$ \\
\hline Female & $49 \%$ & $50 \%$ & $53 \%$ & $76 \%$ & $19 \%$ & $53 \%$ & $41 \%$ & $39 \%$ & $52 \%$ & $50 \%$ \\
\hline \multicolumn{11}{|l|}{ Age, years } \\
\hline Mean & 56 & 60 & 57 & 48 & 56 & 57 & 55 & 56 & 55 & 57 \\
\hline $40-49$ & $31 \%$ & $17 \%$ & $21 \%$ & $65 \%$ & $36 \%$ & $25 \%$ & $33 \%$ & $31 \%$ & $28 \%$ & $24 \%$ \\
\hline $50-59$ & $33 \%$ & $26 \%$ & $38 \%$ & $19 \%$ & $24 \%$ & $34 \%$ & $39 \%$ & $30 \%$ & $44 \%$ & $39 \%$ \\
\hline $60-69$ & $26 \%$ & $40 \%$ & $36 \%$ & $15 \%$ & $33 \%$ & $30 \%$ & $20 \%$ & $26 \%$ & $20 \%$ & $22 \%$ \\
\hline $70-75$ & $10 \%$ & $16 \%$ & $6 \%$ & $1 \%$ & $7 \%$ & $12 \%$ & $9 \%$ & $13 \%$ & $8 \%$ & $16 \%$ \\
\hline \multicolumn{11}{|l|}{ Severity of COPD } \\
\hline Mild & $26 \%$ & $13 \%$ & $42 \%$ & $24 \%$ & $43 \%$ & $17 \%$ & $27 \%$ & $36 \%$ & $13 \%$ & $29 \%$ \\
\hline Moderate & $55 \%$ & $47 \%$ & $51 \%$ & $48 \%$ & $53 \%$ & $58 \%$ & $52 \%$ & $55 \%$ & $71 \%$ & $61 \%$ \\
\hline Severe & $15 \%$ & $26 \%$ & $8 \%$ & $25 \%$ & $4 \%$ & $21 \%$ & $17 \%$ & $9 \%$ & $14 \%$ & $8 \%$ \\
\hline Very severe & $4 \%$ & $14 \%$ & $0 \%$ & $3 \%$ & $0 \%$ & $4 \%$ & $3 \%$ & $0 \%$ & $2 \%$ & $2 \%$ \\
\hline \multicolumn{11}{|c|}{ Time since COPD diagnosis, years } \\
\hline Mean & 4.7 & 7.3 & 4.2 & 3.6 & 5.0 & 4.9 & 5.0 & 4.8 & 3.4 & 3.4 \\
\hline \multicolumn{11}{|l|}{ COPD diagnosis by } \\
\hline $\begin{array}{l}\text { General physician/ } \\
\text { primary care physician }\end{array}$ & $32 \%$ & $15 \%$ & $47 \%$ & $26 \%$ & $39 \%$ & $16 \%$ & $33 \%$ & $37 \%$ & $53 \%$ & $37 \%$ \\
\hline Pulmonologist & $68 \%$ & $85 \%$ & $53 \%$ & $74 \%$ & $61 \%$ & $84 \%$ & $67 \%$ & $63 \%$ & $47 \%$ & $63 \%$ \\
\hline
\end{tabular}

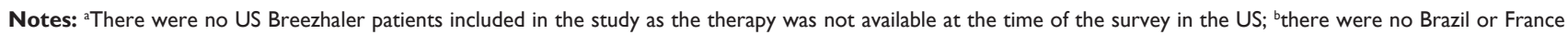
Genuair patients included in the study as the therapy was not available at the time of the survey in Brazil or France; ${ }^{\mathrm{C}}$ Total number of patients was lower than sum of patients by device as some patients were using multiple devices.

Abbreviation: COPD, chronic obstructive pulmonary disease.

(Figure 2) for training methods were demonstration of inhaler use $(83 \%)$ followed by video $(58 \%)$, instructions for use (51\%), and leaflet (34\%).

Twenty-nine percent (29\%) of patients had not been checked to see if they were using their device correctly within the last 2 years. Patients who were checked were significantly more adherent than unchecked patients $(p=0.020)$. Patients who were checked for inhaler technique felt more confident that they received the full dose compared to those who were unchecked. Potential medication errors were identified as repeating dose (overdosing with Genuair and Ellipta) when not confident, or incorrect dosing (eg, underdosing

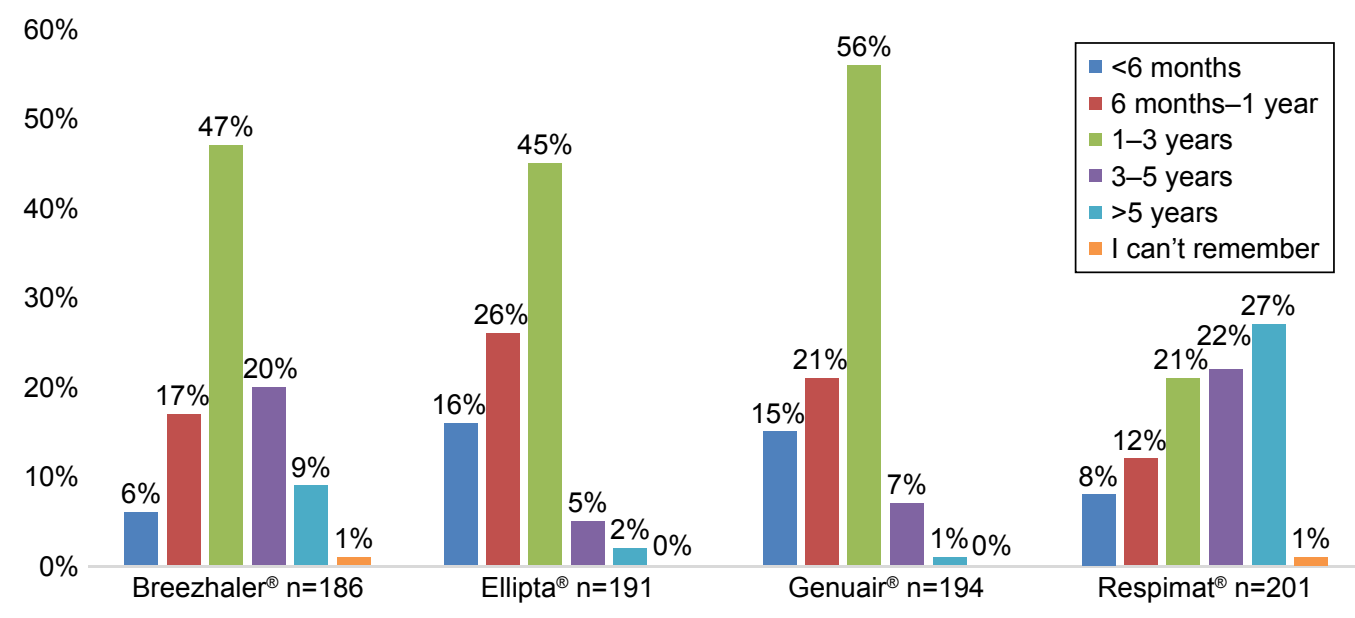

Figure I Length of use by device. 
Table 3 Patient disease severity and age

\begin{tabular}{|c|c|c|c|c|c|c|c|c|c|}
\hline & & \multicolumn{8}{|c|}{ Age group } \\
\hline & & \multicolumn{2}{|c|}{$\begin{array}{l}40-49 \\
\text { years } \\
n=236\end{array}$} & \multicolumn{2}{|c|}{$\begin{array}{l}50-59 \\
\text { years } \\
\mathrm{n}=\mathbf{2 4 8}\end{array}$} & \multicolumn{2}{|c|}{$\begin{array}{l}60-69 \\
\text { years } \\
n=202\end{array}$} & \multicolumn{2}{|c|}{$\begin{array}{l}70-75 \\
\text { years } \\
n=78\end{array}$} \\
\hline & & $\mathbf{n}$ & $\%$ & $\mathbf{n}$ & $\%$ & $\mathbf{n}$ & $\%$ & $\mathbf{n}$ & $\%$ \\
\hline \multirow[t]{4}{*}{ Severity } & Mild & $81^{a}$ & 34 & 62 & 25 & 39 & 19 & 15 & 19 \\
\hline & Moderate & 126 & 53 & $152^{\mathrm{b}}$ & 61 & 109 & 54 & 34 & 44 \\
\hline & Severe & 27 & 11 & 30 & 12 & $43^{c}$ & 21 & $18^{d}$ & 23 \\
\hline & Very severe & 2 & I & 4 & 2 & 11 & 5 & $1 I^{\mathrm{e}}$ & 14 \\
\hline
\end{tabular}

Notes: ${ }^{a} p=0.001$ (comparison to $60-69$ years); $p=0.006$ (comparison to $70-75$ years); ${ }^{c} p=0.005$ (comparison to $40-49$ years); ${ }^{d} p=0.01$ I (comparison to $40-49$ years); ${ }^{\mathrm{e}} p=0.00$ I (comparison to $40-49$ and $50-59$ years).

with Respimat). Checked patients also felt more confident that they received the full dose compared to those who were unchecked (Table 6).

Patient-reported inhaler treatment adherence in the last 30 days was highest with Breezhaler followed by Respimat, Ellipta, and Genuair (Figure 3). Patient-reported inhaler treatment adherence was significantly higher with Breezhaler (90\%) versus Ellipta (65\%) $(p=0.001)$. Significantly more patients felt confident or very confident of having taken their full dose of medication with Breezhaler versus patients using Ellipta ( $p=0.001)$ or patients using Respimat $(p=0.001)$ (Table 7). Ninety-three percent felt confident or very confident of having taken the full dose with Breezhaler, and this was more than any that reported for any other device (Table 7). Most patients reported being confident (34\%-54\%) or very confident $(24 \%-59 \%)$ of having taken the full dose (Table 7). Of the patients who did not feel confident, more patients reported overdosing with Genuair, Ellipta, and Respimat (33.2\%, 29.4\%, and $21.4 \%$, respectively). Only few patients reported overdosing using Breezhaler

Table 4 Patient adherence

\begin{tabular}{|c|c|c|c|c|c|c|}
\hline & & \multicolumn{2}{|c|}{$\begin{array}{l}\text { Adherent } \\
n=539\end{array}$} & \multicolumn{2}{|c|}{$\begin{array}{l}\text { Nonadherent } \\
n=225\end{array}$} & \multirow[t]{2}{*}{$p$-value } \\
\hline & & $\bar{n}$ & $\%$ & $\mathrm{n}$ & $\%$ & \\
\hline \multirow[t]{2}{*}{ Gender } & Male & 276 & 51 & 117 & 52 & $p=0.84 I$ \\
\hline & Female & 263 & 49 & 108 & 48 & \\
\hline \multirow[t]{2}{*}{ Age } & $\leq 65$ years & 412 & 76 & 189 & 84 & $p=0.020$ \\
\hline & $>65$ years & 127 & 24 & 36 & 16 & \\
\hline \multirow[t]{4}{*}{ Severity } & Mild & $|4|$ & 26 & 56 & 25 & $p=0.71 I$ \\
\hline & Moderate & 288 & 53 & 133 & 59 & $p=0.150$ \\
\hline & Severe & 86 & 16 & 32 & 14 & $p=0.549$ \\
\hline & Very severe & 24 & 4 & 4 & 2 & $p=0.073$ \\
\hline \multirow[t]{2}{*}{$\begin{array}{l}\text { Time since } \\
\text { diagnosis }\end{array}$} & $\begin{array}{l}\text { Newly diagnosed } \\
\text { ( } \leq 12 \text { months) }\end{array}$ & 81 & 15 & 45 & 20 & $p=0.091$ \\
\hline & $\begin{array}{l}\text { Long time diagnosis } \\
\text { ( }>12 \text { months) }\end{array}$ & 458 & 85 & 180 & 80 & \\
\hline
\end{tabular}

Table 5 Trained and untrained patient influencers

\begin{tabular}{|c|c|c|c|c|c|c|}
\hline & & \multicolumn{2}{|c|}{$\begin{array}{l}\text { Trained } \\
\text { patients } \\
n=535\end{array}$} & \multicolumn{2}{|c|}{$\begin{array}{l}\text { Untrained } \\
\text { patients } \\
\mathbf{n}=\mathbf{2 2 5} \\
\end{array}$} & \multirow[t]{2}{*}{$p$-value } \\
\hline & & $\mathrm{n}$ & $\%$ & $\mathrm{n}$ & $\%$ & \\
\hline \multirow[t]{2}{*}{ Adherence } & Compliant & 356 & 67 & 181 & 80 & $p=0.001$ \\
\hline & Noncompliant & 179 & 33 & 44 & 20 & \\
\hline Confidence & Low confidence & 15 & 3 & 17 & 8 & $p=0.003$ \\
\hline that full dose & Neutral & 53 & 10 & 43 & 19 & $p=0.001$ \\
\hline has been taken & Confident & 467 & 87 & 165 & 73 & $p=0.00 \mathrm{I}$ \\
\hline Correct dosing & Correct dosing & 448 & 84 & 180 & 80 & $p=0.215$ \\
\hline
\end{tabular}

(4.4\%) (Table 7). The majority of patients had correct dosing of their COPD medication (Figure 4).

\section{Discussion}

The REAL survey was a computer-assisted, telephonic survey in COPD patients which gathered real-world information on correct inhaler use, inhalation technique, and device attributes, as well as adherence and dosing accuracy, training, correct device use, ease of use, and factors that influence patient adherence in commercially available inhalers delivering COPD maintenance therapy via the Breezhaler, Ellipta, Genuair, and Respimat devices.

Disease severity was similar across patients utilizing different devices. Severity of disease was significantly different with respect to age; older patients were more likely to have greater disease severity. Patients with mild disease were primarily younger, while those with severe to very severe disease were predominately older.

Patient-reported inhaler treatment adherence in the last 30 days was highest with Breezhaler followed by Respimat, Ellipta, and Genuair. Adherence was lower in younger patients compared to older patients. This may be due to milder disease severity in younger patients. Patients with milder disease may not see the need to regularly take their prescribed medication as they may believe that their symptoms are not serious or their condition is controlled. Gender, disease severity, or time since diagnosis did not influence adherence. Patient-reported inhaler treatment adherence was highest with Breezhaler followed by Respimat, Ellipta, and Genuair.

Training is integral to effective device use and subsequent disease control. Misuse of inhalers has been linked to poor disease control. ${ }^{17} \mathrm{COPD}$ guidelines recommend that inhaler training should be continually assessed at subsequent clinic visits. Where necessary, retraining should be provided. ${ }^{16}$ The benefits of training were demonstrated in this study, where training with a demonstration was common among 


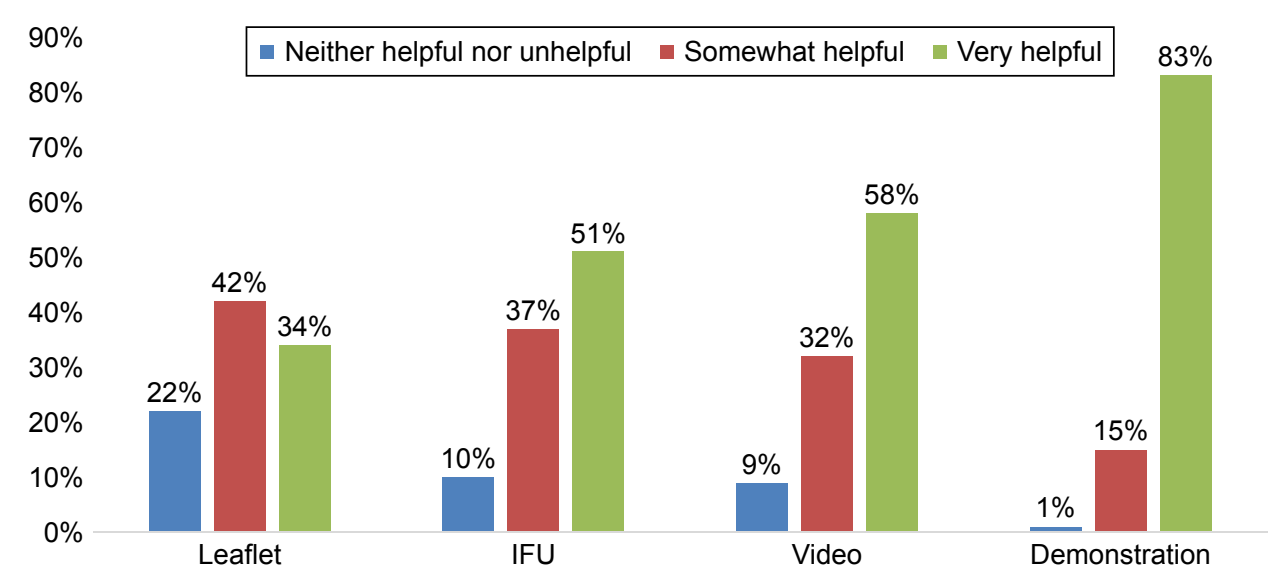

Figure 2 Patient preferences for using different training methods. Abbreviation: IFU, instructions for use.

adherent patients. These patients were more often trained by a pulmonologist. General practitioners who diagnose the patient were more likely to delegate training to pulmonologists, pharmacists, and nurses. Gender, age, disease severity, or time since diagnosis were not factors that influenced correct dosing. However, trained patients were more confident that the correct dose was taken. When patients did not feel confident of having received the full dose, they reported having inhaled another dose at the same time or at a later time (overdosing). The majority of patients were more confident of having taken their full dose of medication with Breezhaler versus Ellipta, Genuair, or Respimat. Patients who were checked for correct device usage were more adherent than unchecked patients. These checked patients also felt more confident that they received the full dose. Evidence suggests that patients prefer inhalers that provide feedback on dose administration and find such devices easy to use (patients are more likely to adhere to the prescribed treatment when they use such an inhaler). ${ }^{17}$ Adherent patients were more compliant when their inhaler technique was checked compared to unchecked patients. Inhaler use has been frequently

Table 6 Adherence and optimal inhaler use in checked and unchecked patients

\begin{tabular}{|c|c|c|c|c|c|c|}
\hline & & \multicolumn{2}{|c|}{$\begin{array}{l}\text { Checked } \\
\text { patients } \\
n=524\end{array}$} & \multicolumn{2}{|c|}{$\begin{array}{l}\text { Unchecked } \\
\text { patients } \\
n=240\end{array}$} & \multirow[t]{2}{*}{$p$-value } \\
\hline & & $\bar{n}$ & $\%$ & $\bar{n}$ & $\%$ & \\
\hline \multirow[t]{2}{*}{ Adherence } & Compliant & 383 & 73 & 156 & 65 & $p=0.020$ \\
\hline & Noncompliant & $14 \mid$ & 27 & 84 & 35 & \\
\hline Confidence & Low confidence & 18 & 3 & 14 & 6 & $p=0.123$ \\
\hline that full dose & Neutral & 50 & 10 & 46 & 19 & $p=0.001$ \\
\hline has been taken & Confident & 456 & 87 & 180 & 75 & $p=0.001$ \\
\hline Correct dosing & Correct dosing & 426 & 81 & 205 & 85 & $p=0.165$ \\
\hline
\end{tabular}

reported as suboptimal. ${ }^{19}$ Drivers of adherence are paramount to COPD disease management. Inhalers are the key route of administration. Checking of inhaler use contributes toward optimal and correct inhaler use.

HCPs should be aware of predictive factors for patient adherence including patient age. Younger patients are significantly less compliant with milder disease severity. Patients should be trained to use their inhalers correctly by HCPs using effective training methods so as to achieve the full benefit of inhaled therapy. Correct inhaler technique should be assessed at subsequent follow-ups. HCPs should be aware that individual device attributes may influence patient adherence and confidence of dosage. Many patients with COPD achieve incomplete benefit from their treatment, due to inadequate device training or incorrect inhaler technique. Inhaler overuse and underuse are the most common forms of nonadherence. Overall, this leads to inhaler use errors and may negatively impact treatment adherence. This survey shows low incidence of training or monitoring (by HCPs) for correct inhaler use.

Devices that provide low confidence of having inhaled the full dose may result in underuse or overuse of medication, which may also impact efficacy and/or safety outcomes in patients. Thus, there is a need for enhancing the $\mathrm{HCP}$-patient interaction through effective training programs. Considering that patients with COPD self-administer their medication, these insights should be considered for successful management of COPD.

Limitations of the survey were that measures of patient adherence were based on patient report. Additionally, there may have been possible selection bias and recall bias. The survey was also not a randomized trial and reflected realworld experience. 


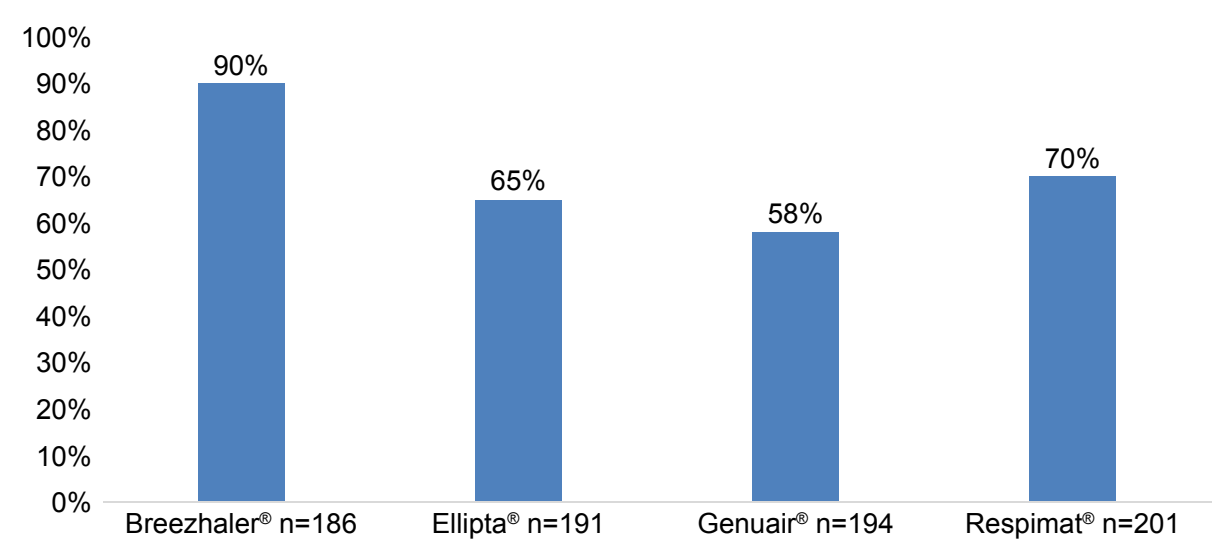

Figure 3 Self-reported adherence with COPD medication in last 30 days.

Abbreviation: COPD, chronic obstructive pulmonary disease.

Table 7 Patient-reported confidence of taking full and self-reported correct dose

\begin{tabular}{|c|c|c|c|c|}
\hline Parameter & Breezhaler $^{\circledR}$ & Ellipta $^{\circledR}$ & Genuair $^{\circledR}$ & Respimat $^{\circledR}$ \\
\hline Confident or very confident of having taken the full dose & $93 \%$ & $80 \%$ & $84 \%$ & $76 \%$ \\
\hline $\begin{array}{l}\text { "When you think you feel you have not had a full dose, what } \\
\text { do you typically do? - I inhale another dose at the same time" }\end{array}$ & $4 \%$ & $25 \%$ & $33 \%$ & $15 \%$ \\
\hline Patients taking correct dose $\mathrm{e}^{\mathrm{a}}$ & $97 \%$ & $93 \%$ & $91 \%$ & $50 \%$ \\
\hline
\end{tabular}

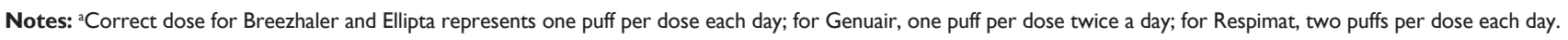

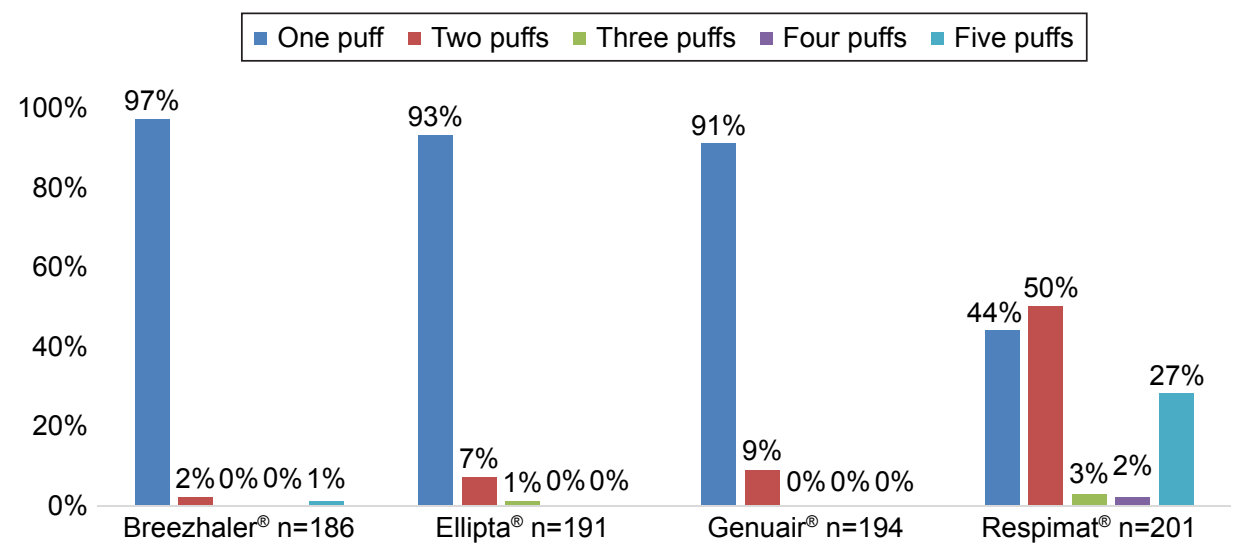

Figure 4 Proportion of device correct dosing.

\section{Conclusion}

The results presented are of significant importance as device attributes that lead to confidence of full dose received may improve treatment adherence by reducing the risk of overdosing or underdosing drug administration in patients. Further investigation into the factors of medication errors is still required. Inhalers play a crucial role in the effective management of patients with COPD; it is therefore important that patients have full confidence in the use of their inhaler.

\section{Acknowledgment}

The authors thank Clarice Field $(\mathrm{PhD})$ and Paul McKiernan $(\mathrm{PhD})$ of Novartis for providing medical writing support, which was funded by Novartis AG, Basel, Switzerland, in accordance with Good Publication Practice (GPP3) guidelines (http://www.ismpp.org/gpp3). Pankaj Goyal and Joao Mendes, Novartis Pharma AG, Basel, contributed to the design and conceptualization of study. The survey was designed by PDD, London, United Kingdom, and GfK Switzerland AG, Basel, Switzerland. The survey was conducted by GfK Switzerland AG, Basel, Switzerland, and sponsored by Novartis Pharma AG, Basel, Switzerland.

\section{Disclosure}

DLK, VB, and FSG are all employees of Novartis and have received no other funding. MG and SW are employees of 
GfK Switzerland AG and have received no other funding. Professor David Price has board membership with Aerocrine, Amgen, AstraZeneca, Boehringer Ingelheim, Chiesi, Mylan, Mundipharma, Napp, Novartis, and Teva Pharmaceuticals; consultancy agreements with Almirall, Amgen, AstraZeneca, Boehringer Ingelheim, Chiesi, GlaxoSmithKline, Mylan, Mundipharma, Napp, Novartis, Pfizer, Teva Pharmaceuticals, and Theravance; grants and unrestricted funding for investigator-initiated studies (conducted through Observational and Pragmatic Research Institute Pte Ltd) from Aerocrine, AKL Research and Development Ltd, AstraZeneca, Boehringer Ingelheim, British Lung Foundation, Chiesi, Mylan, Mundipharma, Napp, Novartis, Pfizer, Respiratory Effectiveness Group, Teva Pharmaceuticals, Theravance, UK National Health Service, Zentiva; payment for lectures/ speaking engagements from Almirall, AstraZeneca, Boehringer Ingelheim, Chiesi, Cipla, GlaxoSmithKline, Kyorin, Mylan, Merck, Mundipharma, Novartis, Pfizer, Skyepharma, and Teva Pharmaceuticals; payment for manuscript preparation from Mundipharma and Teva Pharmaceuticals; payment for the development of educational materials from Mundipharma and Novartis; payment for travel/accommodation/ meeting expenses from Aerocrine, AstraZeneca, Boehringer Ingelheim, Mundipharma, Napp, Novartis, and Teva Pharmaceuticals; funding for patient enrolment or completion of research from Chiesi, Novartis, Teva Pharmaceuticals, and Zentiva; stock/stock options from AKL Research and Development Ltd which produces phytopharmaceuticals; owns 74\% of the social enterprise Optimum Patient Care Ltd (Australia, Singapore, and UK) and 74\% of Observational and Pragmatic Research Institute Pte Ltd (Singapore); and is peer reviewer for grant committees of the Efficacy and Mechanism Evaluation Programme, and Health Technology Assessment. The authors report no other conflicts of interest in this work.

\section{References}

1. Lavorini F. Inhaled drug delivery in the hands of the patient. $J$ Aerosol Med Pulm Drug Deliv. 2014;27(6):414-418.

2. Dolovich MB, Ahrens RC, Hess DR, et al. Device selection and outcomes of aerosol therapy: evidence-based guidelines: American College of Chest Physicians/American College of Asthma, Allergy, and Immunology. Chest. 2005;127(1):335-371.

International Journal of COPD

\section{Publish your work in this journal}

The International Journal of COPD is an international, peer-reviewed journal of therapeutics and pharmacology focusing on concise rapid reporting of clinical studies and reviews in COPD. Special focus is given to the pathophysiological processes underlying the disease, intervention programs, patient focused education, and self management protocols.

Submit your manuscript here: http://www.dovepress.com/international-journal-of-chronic-obstructive-pulmonary-disease-journal published authors.
3. Lavorini F, Fontana GA. Inhaler technique and patient's preference for dry powder inhaler devices. Expert Opin Drug Deliv. 2014; 11(1):1-3.

4. Anderson P. Patient preference for and satisfaction with inhaler devices. European Res Rev. 2005;14(96):109-116.

5. Berger BA. Assessing and interviewing patients for meaningful behavioral change: Part 1. Case Manager. 2004;15(5):46-50; quiz 51.

6. Braido F, Chrystyn H, Baiardini I, et al. "Trying, But Failing” - the role of inhaler technique and mode of delivery in respiratory medication adherence. J Allergy Clin Immunol Pract. 2016;4(5):823-832.

7. Vrijens B, Dima AL, Van Ganse E, et al. What we mean when we talk about adherence in respiratory medicine. J Allergy Clin Immunol Pract. 2016;4(5):802-812.

8. Fink JB, Rubin BK. Problems with inhaler use: a call for improved clinician and patient education. Respir Care. 2005;50(10):1360-1374; discussion 1374-1365.

9. Lavorini F, Magnan A, Dubus JC, et al. Effect of incorrect use of dry powder inhalers on management of patients with asthma and COPD. Respir Med. 2008;102(4):593-604.

10. Chrystyn H, Price DB, Molimard M, et al. Comparison of serious inhaler technique errors made by device-naive patients using three different dry powder inhalers: a randomised, crossover, open-label study. $B M C$ Pulm Med. 2016;16:12.

11. Bosnic-Anticevich S, Chrystyn H, Costello RW, et al. The use of multiple respiratory inhalers requiring different inhalation techniques has an adverse effect on COPD outcomes. Int J Chron Obstruct Pulmon Dis. 2017;12:59-71.

12. Price DB, Roman-Rodriguez M, McQueen RB, et al. Inhaler errors in the CRITIKAL study: type, frequency, and association with asthma outcomes. J Allergy Clin Immunol Pract. 2017;5(4):1071-1081.

13. Molimard M, Raherison C, Lignot S, et al. Chronic obstructive pulmonary disease exacerbation and inhaler device handling: real-life assessment of 2935 patients. Eur Respir J. 2017;49(2). pii: 1601794.

14. Miravitlles M, Montero-Caballero J, Richard F, et al. A cross-sectional study to assess inhalation device handling and patient satisfaction in COPD. Int J Chron Obstruct Pulmon Dis. 2016;11:407-415.

15. Bosnic-Anticevich SZ, Sinha H, So S, Reddel HK. Metered-dose inhaler technique: the effect of two educational interventions delivered in community pharmacy over time. J Asthma. 2010;47(3):251-256.

16. Global Strategy for the Diagnosis, Management and Prevention of COPD, Global Initiative for Chronic Obstructive Lung Disease (GOLD); 2017. Available from: http://goldcopd.org. Accessed August 6, 2017.

17. Molimard M, Colthorpe P. Inhaler devices for chronic obstructive pulmonary disease: insights from patients and healthcare practitioners. J Aerosol Med Pulm Drug Deliv. 2015;28(3):219-228.

18. Chrystyn H, Small M, Milligan G, Higgins V, Gil EG, Estruch J. Impact of patients' satisfaction with their inhalers on treatment compliance and health status in COPD. Respir Med. 2014;108(2):358-365.

19. Sanchis J, Gich I, Pedersen S; Aerosol Drug Management Improvement Team (ADMIT). Systematic review of errors in inhaler use: has patient technique improved over time? Chest. 2016;150(2):394-406.

This journal is indexed on PubMed Central, MedLine and CAS. The manuscript management system is completely online and includes a very quick and fair peer-review system, which is all easy to use. Visit $\mathrm{http}: / / \mathrm{www}$.dovepress.com/testimonials.php to read real quotes from 